Research Article

Open Access

\title{
Alteration in Cytokine Gene Expression in Hypertrophic Scars with Herbal Therapy
}

\author{
Vaibhav Jain 1 , Jyoti Gupta1, Shuchi Jain ${ }^{2 \star}$, Madhu Jain ${ }^{2}$, NG Kostopoulos ${ }^{3}$ and Pradeep Jain ${ }^{1}$ \\ ${ }^{1}$ Department of Plastic Surgery, Institute of Medical Sciences, Banaras Hindu University, Varanasi, India \\ 2Department of Obstetrics and Gynaecology, Institute of Medical Sciences, Banaras Hindu University, Varanasi, India \\ ${ }^{3}$ Director Holistic Health Centre, Athens, Greece
}

\section{Article Info

*Corresponding author:
Shuchi Jain
Assistant Professor
Department of Obstetrics and Gynaecology
Institute of Medical Sciences
Banaras Hindu University
Varanasi
India
E-mail: shuchi.gyno81@gmail.com

Received: June 22, 2018

Accepted: July 9, 2018

Published: July 13, 2018

Citation: Jain V, Gupta J, Jain S, Jain M, Kostopoulos NG, Jain P. Alteration in Cytokine Gene Expression in Hypertrophic Scars with Herbal Therapy. Madridge J Surg. 2018; 1(2): 40-43.

doi: $10.18689 / \mathrm{mjs}-1000110$

Copyright: @ $₫ 2018$ The Author(s). This work is licensed under a Creative Commons Attribution 4.0 International License, which permits unrestricted use, distribution, and reproduction in any medium, provided the original work is properly cited.

Published by Madridge Publishers

\begin{abstract}
Introduction: In spite of many advances in management of hypertrophic scars, the lesions remain difficult to prevent and treat. There is also no consensus regarding the best treatment to reduce or prevent hypertrophic scarring. Many herbal preparations have been used from time to time but no study has been carried out to evaluate the changes in gene expression of cytokines following their application.
\end{abstract}

Materials and Methods: Eighty five patients with hypertrophic scar, eighteen months or more in duration, were part of the study. The last thirty of these patients, after informed consent, were subjected to biopsy of hypertrophic scars and blood sampling before starting the herbal cream application and then after 6 months of continuous application for expression of cytokines, TGF $\beta 1$ and TNF $\alpha$. Clinical response was assessed in all the 85 patients by using Vancouver Scar Scale (VSS) and POSAS (Patient Observer Scar Assessment Scale) before and after the treatment. There were thirty controls.

Results: The VSS showed significant improvement in the hypertrophic scars treated with the herbal cream at 6 months of continuous use. The POSAS in our study also revealed remarkable improvement in the appearance of scar and other associated symptoms like pain and itching, with good to excellent response in $81.16 \%$ (a more than 4 points improvement based on VSS scale). One to three points' improvement was seen in 16 (18.82\%) cases on POSAS. There was down-regulation of TGF $\beta 1$ and TNF $\alpha$ gene expression wasincreased at 6 months of treatment.

Conclusion: The herbal cream in use in the study significantly improved the hypertrophic scar not only on the surface but alsoat the cellular and molecular levels as characterized by down-regulation of TGF $\beta 1$ and up-regulation of TNF $\alpha$.

Keywords: Hypertrophic Scar; Herbal Cream and Scars; Cytokines Gene Expression.

\section{Introduction}

Although management of hypertrophic scars has advanced in the past several years, the lesions remain difficult to prevent and treat. The hypertrophic scars after burns require a special approach as the scars are usually widespread. There is also no consensus regarding the best treatment to reduce or prevent hypertrophic scarring. Recurrences remain common and satisfaction of patients is variable.

\section{Aims and Objectives}

1. To evaluate the clinical response of hypertrophic scars to herbal cream

2. To evaluate the expression of Transforming Growth Factor (TGF) $\beta 1$ and Tumour Necrosis Factor $\alpha$ (TNF $\alpha$ ) in scar tissue and blood and their response to herbal cream. 


\section{Materials and Methods}

Eighty five patients with hypertrophic scar, eighteen months or more in duration, were part of the study. The patients already under some treatment were excluded. The last thirty of these patients, after informed consent, were subjected to biopsy of hypertrophic scars and blood sampling before starting the herbal cream application and then after 6 months of continuous application for expression of cytokines, TGF $\beta 1$ and TNF $\alpha$. Clinical response was assessed in all the 85 patients by using Vancouver Scar Scale and POSAS (Patient Observer Scar Assessment Scale on visual analog scale from 1 to 10) before and after the treatment.

Thirty controls such as patients undergoing plastic surgical procedure for conditions other than hypertrophic scars and willing to participate in the study were taken. Obtained data was analyzed and compared with control group to know the relation between changes in the level of cytokines and clinical appearance of hypertrophic scars.

\section{Isolation of total RNA}

Total RNA was extracted from the samples using Trizol reagent (Invitrogen, Carlsbad, CA) according to the manufacturer's recommendations and analyzed on agarose gel followed by gel documentation system and visualized by ethidium bromide staining.

\section{PCR Based cytokine analysis}

Reverse transcription PCR was done for the Gene expression of TNF- $\alpha$ \& TGF- $\beta 1$ genes.

\section{Description of herbal cream}

It (Divine Burns Cream) contained Shorearobusta.

Licensed under - Ayurvedic drug category.

License - Ayurvedic drug manufacturing license No-GA/741 Form No- 25D, approved by Food and Drugs Controller of Gujarat on 2-8-2008.

\section{Statistical analysis}

The package program SPSS (Statistical Package for Social Sciences for Windows 16.0) was used for statistical analysis. Student t- test was used to compare the means of parametric data.

\section{Results}

The VSS showed significant improvement in the hypertrophic scars treated with the herbal cream at 6 months of continuous use [Table 1]. The POSAS in our study also revealed remarkable improvement in the appearance of scar and other associated symptoms like pain and itching, with good to excellent response in $81.16 \%$ (a more than 4 points improvement based on VSS scale; Fig. $1 \& 2$ ). One to three points' improvement was seen in 16 (18.82\%) cases on POSAS [Table 2].

Table 1. VSS score at start and 6 months of treatment

\begin{tabular}{|c|c|c|c|}
\hline Group & Mean \pm SD & t-value & p-value \\
\hline VSS at 0 month & $9.54 \pm 2.44$ & \multirow{2}{*}{12.240} & $<0.001$ \\
\hline VSS 6 months & $5.32 \pm 2.87$ & & \\
\hline
\end{tabular}

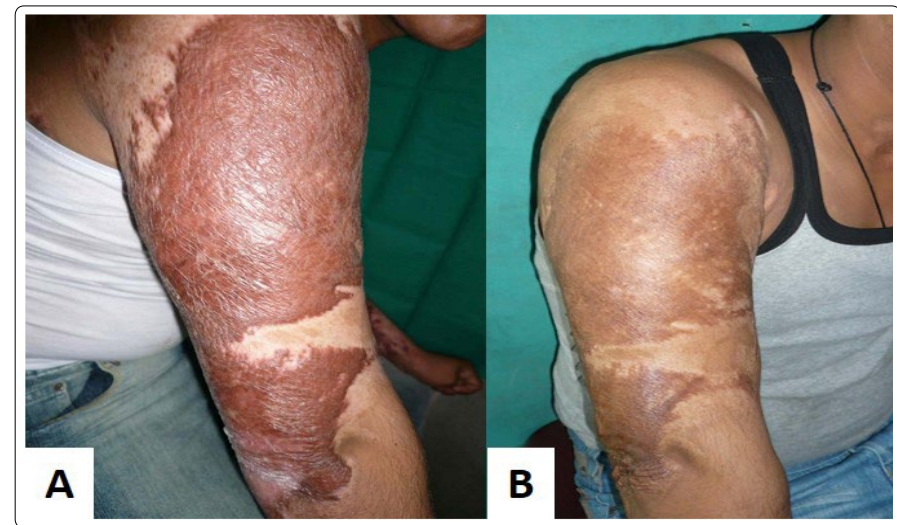

Figure 1. Hypertrophic scar over right shoulder and arm A: Before herbal therapy; B: At 6 months post-therapy

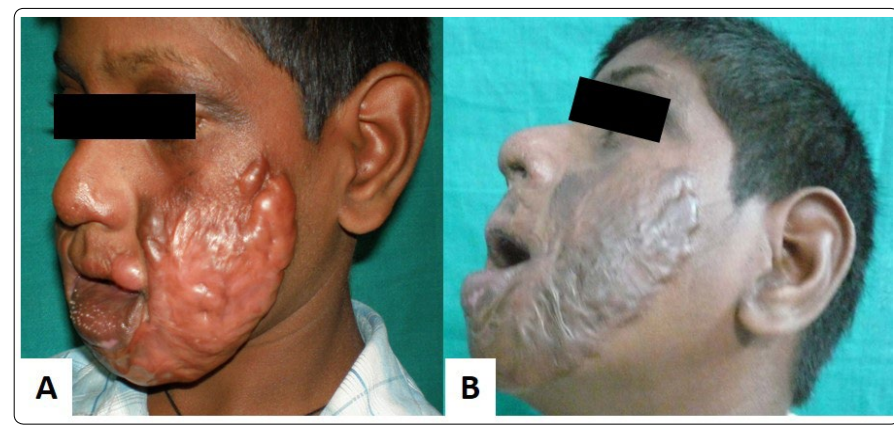

Figure 2. Hypertrophic scar over middle and lower face in a young boy A: Pre-therapy; B: At 6 months post-therapy

Table 2. Patients' Observer Scar Assessment after 6 months

\begin{tabular}{|c|c|c|}
\hline Response & Scar & Percentage \\
\hline Excellent & 29 & $34.11 \%$ \\
\hline Good & 40 & $47.05 \%$ \\
\hline Mild & 16 & $18.82 \%$ \\
\hline No response & - & - \\
\hline
\end{tabular}

We failed to isolate the RNA from blood in 18 and 20 patients before and after the treatment respectively but only in 5 from the tissue on both the occasions.

Transforming growth factor - beta 1 could be detected in 12 and 2 blood samples but from the tissue in 30 and 22 samples before and after the treatment respectively [Table 3]. Tumor necrosis factor- alpha was detected in 3 and 1 blood samples and from the scar tissue in 21 and 14 samples before and after the treatment respectively [Table 3].

Table 3. Number of patients with isolation of RNA and characterization of gene (TGF $\beta 1$ and TNF $\alpha$ )

\begin{tabular}{|c|c|c|c|c|c|c|}
\hline & \multicolumn{2}{|c|}{ RNA Isolated } & \multicolumn{2}{c|}{ TGF $\boldsymbol{\beta}$ Isolated } & \multicolumn{2}{c|}{ TNF $\boldsymbol{\alpha}$ Isolated } \\
\cline { 2 - 7 } Sample & At Start & At 6 Months & At Start & At 6 Months & At Start & At 6 Month \\
\hline Blood (30) & 12 & 10 & 12 & 2 & 3 & 1 \\
\hline Tissue (30) & 25 & 25 & 30 & 22 & 21 & 14 \\
\hline
\end{tabular}

In all the samples, we did only the qualitative assessment of TGF $\beta 1$ and TNF $\alpha$. We judged the up-regulation, downregulation and absence of particular gene expression on the basis of intensity and width of the band or presence and absence of the band inthe specific base pair region on Agarose gel electrophoresis.

There was down-regulation of TGF $\beta 1$ in 22 and 2 samples from tissue and blood respectively at 6 months of treatment. The band was absent in TGF $\beta 1$ specific base pair region in 10 blood and 8 tissue samples.TNF $\alpha$ gene expression was further increased in 14 tissues and 1 blood samples after completion 
of 6 months of treatment. 7 scar tissue and 2 blood samples had band comparable to that in normal individualin base pair region respective for TNF $\alpha$ gene [Table 4].

Table 4. Expressions of TGF $\beta 1$ and TNF $\alpha 6$ months after the treatment

\begin{tabular}{|c|c|c|c|c|c|c|}
\hline & \multicolumn{2}{|c|}{ Down regulation } & \multicolumn{2}{c|}{ Complete absence of band } & \multicolumn{2}{c|}{ No Change in band } \\
\cline { 2 - 7 } & Tissue & Blood & Tissue & Blood & Tissue & Blood \\
\hline TGF $\beta 1$ & 22 & 2 & 8 & 10 & 0 & 0 \\
\hline TNF $\alpha$ & 14 & 1 & 7 & 2 & 0 & 0 \\
\hline
\end{tabular}

On the analysis of 30 skin and blood samples taken as controls, we characterized the gene in all tissue samples of normal individuals. We found band for both genes in all the normal skin biopsy samples comparable to that seen in patients with down-regulation of TGF $\beta 1$ and upregulation of TNF $\alpha$. Statistical analysis done with student's t test application revealed statistically significant $(p<.05)$ alteration in level of both genes (in scar tissue), 6 months after completion of treatment with improved clinical outcome. However we could not obtain any correlation between gene expressions in blood and clinical outcome because of very few blood samples revealing their presence.

\section{Discussion}

With the progress in science and technology, we are now able to understand some factors at tissue and genetic level, responsible for wound healing and scar formation which was not possible earlier. Different modalities for management of adverse scars have been employed worldwide which include surgery, different allopathic drugs, Herbal and Ayurvedic preparations, pressure garment, silicone gel sheet, radiotherapy, cryotherapy and LASER but none of them is accepted as a gold standard method. Every method alone or in combination has its own benefits and drawbacks and not applicable to all the patients with hypertrophic scar or keloid.

As there is lack of consensus on the aetiology of hypertrophic scars, the therapeutic options are also too many, with every one claiming one particular modality to be more promising over the other. Right from pressure therapy $[1,2]$ and intralesional Triamcinolone $[3,4]$, several newer modalities have been brought out like Lasers [5, 6], Interferons [7, 8], 5- Fluorouracil [9], and Bleomycin [10]. At the other extreme, simple massagehas also been reported to be effective [11]. However, some have not found any appreciable effect of massage on vascularity, pliability, and the thickness of the hypertrophic scar [12].

Koc et al.compared intralesional triamcinolone acetonide (TAC) alone or combined with onion extract in keloidal and hypertrophic scars [13]. Although there was statistically significant improvement in both treatment groups $(p<.05)$, TAC with onion extract was more effective than TAC alone in terms of pain-sensitiveness, itching, and elevation but not in erythema and in duration.

Combining the onion extract with heparin and allantoin did not alter the picture was found by Karagoz et al. who compared silicone gel, silicone gel sheet and the combination of onion extract, heparin and allantoin in treatment of postburn scars of less than 6 months durationand concluded that the silicone gel or gel sheet was superior to the combination of onion extract, heparin and allantoin [14].

Out of herbs known for wound healing, Azadirachtaindica (neem) is a well known herbal medicine used in many skin diseases. Curcuma longa (turmeric) has number of uses in wound healing. Shorea species products have a therapeutic role in skin diseases and wound care. Sesamumindicum oil also has antioxidants active in wound healing. We have chosen components with well documented action in wound healing and re-epithelialization.

Local and systemic transforming growth factor $\beta$ has been implicated as a profibrotic cytokine in the pathogenesis of many fibrotic conditions [15]. Tredget et al. found significantly higher level of TGF $\beta$ in the serum of patients with post-burn hypertrophic scar [15]. Gragnani et al. reported successful use of topical Tamoxifen in decreasing the expression of TGF $\beta_{1}$ with consequent inhibition of fibroblast proliferation as well as collagen production [16].

TGF $\beta 1$ and TNF $\alpha$ were the cytokines assessed in our study before and after the application of herbal cream. Some authors have assessed the expression of gene and its concentration directly where as others have identified the receptor for particular gene in particular type of cell line like keratinocytes, fibroblast etc [17]. However, we isolated the whole RNA for characterization of gene without quantification and compared the gene expression with baseline findings and expressions in normal skin biopsy. Although we also assessedgene expression in the blood samples, we could do so only in few of the blood samples and failed to draw any conclusion. Most of the authors used only tissue samples for gene expression perhaps for that reason. The answer could be low concentration of TGF 1 and TNF $\alpha$ in blood below the detectable levels or that Cytokines in blood were more sensitive with less $1 / 1 / 2$ than in the tissue. Long duration of hypertrophic scars such as more than 18 months in our patients could also be responsible for poor expression of profibrotic cytokines in blood. A persistent focus in tissues having undergone burn insult with diminished blood supply and tissue hypoxia could also be a cause of higher expression of cytokines in the tissue of hypertrophic scars.

On assessment of agarose gel electrophoresis photographs before application we found high intensity wide band in the region for TGF $\beta 1$ and low intensity for TNF $\alpha$ (as compared to normal skin sample) in 25 and 21 tissue samples respectively. Only 3 blood samples showed down-regulation of TNF $\alpha$ and up-regulation in 12 for TGF $\beta 1$.After 6 months of continuous application of herbal cream, expression of TGF $\beta 1$ gene was found to be down-regulated in 22 tissue and 2 blood samples. TNF $\alpha$ gene expression was however increased in treated patients in 14 tissue and 1 blood samples. Post treatment finding in hypertrophic scar tissue was also comparable to normal skin tissue in relation to gene expression.

Our finding of almost complete absence of TNF $\alpha$ from blood samples and comparatively much less in the scar tissue lends support to the findings of others who had supported the hypothesis that TNF $\alpha$ gene expression was high in normal skin and in normotrophic scar as compared to hypertrophic 
scar and that TNF $\beta$ was the cytokine which had more important role than the TNF $\alpha$ for aetiopathogenesis of adverse scarring [18]. Our findings related to TGF $\beta 1$ also were similar to those of other authors who found TGF $\beta 1$ and $\beta 2$ over expression to be the most consistent finding in hypertrophic scar tissue [17].

Tissue samples from controls in our study showed comparable findings as observed in post treated scar. This makes us conclude that our herbal cream had some anti TGF $\beta 1$ property because of which concentration of cytokine was decreased and came to the level of that in normal skin. In few samples, we could not find any band. We can assume that the cytokine concentration became immeasurable after treatment.

Three TGF $\beta$ isoforms-beta1, beta2 and beta3 share 70$80 \%$ amino acid homology and have distinct distribution patterns. The balance between the three isoforms could determine the outcome of wound healing. The differential expression of TGF-beta receptors could also influence the relation between various isoforms and hypertrophic scarring. The herbal cream might have suppressed the $\beta_{1}$ and $\beta_{2}$ isoforms with their down-regulation or might have up-regulated $\beta_{3}$ isoform which neutralized the proinflammatory ones.

Besides assessing the outcome by photographic documentation and VSS, alteration in level of expression of cytokines, the third dimension of the study was to correlate by histological and transmission electron microscopy to further validate the study. When compared, striking differences were noted in untreated and herbal cream treated scars, especially in the basal cells. Basal cells of untreated scars contained numerous vacuoles generally oriented towards the basal lamina. The basal lamina was also less distinct than that in control skin. The untreated scar dermis was composed of loose, unorganized collagen compared to treated scar, particularly near the basal lamina. Also significant difference was noted in collagen fibers organization and vascularity between untreated and herbal cream treated scars. Collagen fibers showed no specific orientation, rather the overall pattern was usually irregular in untreated scars, and in contrast after 6 months of treatment the scar tissue showed regular pattern with parallel orientation of the collagen fibers with respect to long axis of scar and the epidermis. In addition vascularity got decreased after 6 month of treatment which clinically correlated with colour of the hypertrophic scar improving from purple to pink and further to normal.

\section{Summary and Conclusion}

A prospective study was carried out to evaluate the efficacy of the herbal cream in 85 patients with post-burn hypertrophic scars of 18 months or more in duration after the cream was found to be free of side effects and any untoward systemic effect in a prior pilot study. The scar assessment was done in three ways: (A) Clinical and photographic documentation on Vancouver Scar Scale, (B) Assessment by the patient himself/ herself on a visual analog scale (POSAS) and (C) Expression of cytokines TGF $\beta 1$ and TNF $\alpha$ in the scar tissue and blood before and 6 months after the application of the cream. This three pronged analysis supplemented each other and strengthened the fact that the herbal cream in use in the study was able to bring the changes in the hypertrophic scar not only on the surface that could be visualized by naked eyes but also at the cellular and molecular levels.

\section{References}

1. Mustoe TA, Cooter RD, Gold MH, Hobbs FD, Ramelet AA, Shakespeare PG, et al. International clinical recommendations on scar management. Plast Reconstr Surg. 2002; 110(2): 560-571.

2. Macintyre L, Baird M. Pressure garments for use in the treatment of hypertrophic scars-a review of the problems associated with their use. Burns. 2006; 32(1): 10-15. doi: 10.1016/j.burns.2004.06.018

3. Rockwell WB, Cohen IK, Ehrlich HP. Keloids and hypertrophic scars: a comprehensive review. Plast Reconstr Surg. 1989; 84(5): 827-837.

4. Alster TS, West TB. Treatment of scars: a review. Ann Plast Surg. 1997; 39(4): 418-432.

5. Lupton JR, Alster TS. Laser scar revision. Dermatol Clin. 2002; 20(1): 55-65.

6. Nouri K, Vidulich K, Rivas MP. Lasers for scars: a review. J Cosmet Dermatol. 2006; 5(1): 14-22. doi: 10.1111/j.1473-2165.2006.00217.x

7. Tredget EE, Shankowsky HA, Pannu R, Nedelec B, Iwashina T, Ghahary A, et al. Transforming growth factor-beta in thermally injured patients with hypertrophic scars: effects of interferon alpha-2b. Plast Reconstr Surg. 1998; 102(5): 1317-1328.

8. Lee JP, Jalili RB, Tredget EE, Demare JR, GhaharyA. Antifibrogenic effects of liposome-encapsulated IFN-alpha2b cream on skin wounds in a fibrotic rabbit ear model. J Interferon Cytokine Res. 2005; 25(10): 627-631. doi: 10.1089/jir.2005.25.627

9. Apikian M, Goodman G. Intralesional 5-fluorouracil in the treatment of keloid scars. Australas J Dermatol. 2004; 45(2): 140-143. doi: 10.1111/j.1 440-0960.2004.00072.x

10. Naeini FF, Najafian J, Ahmadpour K. Bleomycin tattooing as a promising therapeutic modality in large keloids and hypertrophic scars. Dermatol Surg. 2006; 32(8): 1023-1029. doi: 10.1111/j.1524-4725.2006.32225.x

11. Roques C. Massage applied to scars. Wound Repair Regen. 2002; 10(2):126128.

12. Field T, Peck M, Krugman S, Tuchel T, Schanberg S, Kuhn C, et al. Burn injuries benefit from massage therapy. J Burn Care Rehabil. 1998; 19(3): 241-244.

13. Koc E, Arca E, Surucu B, Kurumlu Z. An open, randomized, controlled, comparative study of the combined effect of intralesional triamcinolone acetonide and onion extract gel and intralesional triamcinolone acetonide alone in the treatment of hypertrophic scars and keloids. Dermatol Surg. 2008; 34(11): 1507-1514. doi: 10.1111/j.1524-4725.2008.34314.x

14. Karagoz H, Yuksel F, Ulkur E, Evinc R. Comparison of efficacy of silicone gel, silicone gel sheeting, and topical onion extract including heparin and allantoin for the treatment of postburn hypertrophic scars. Burns. 2009; 35(8): 1097-1103. doi: 10.1016/j.burns.2009.06.206

15. Tredget EE1, Wang R, Shen Q, Scott PG, Ghahary A. Transforming growth factor-beta $\mathrm{mRNA}$ and protein in hypertrophic scar tissues and fibroblasts: antagonism by IFN-alpha and IFN-gamma in vitro and in vivo. $J$ Interferon Cytokine Res. 2000; 20(2): 143-151. doi: 10.1089/107999000312540

16. Gragnani A, Warde M, Furtado F, Ferreira LM. Topical tamoxifen therapy in hypertrophic scars or keloids in burns. Arch Dermatol Res. 2010; 302(1): 1-4. doi: 10.1007/s00403-009-0983-1

17. Hakvoort T, Altun V, van Zuijlen PP, de Boer WAAM, van der Kwast TH, et al. Transforming growth factor-beta1,-beta2,-beta3, basic fibroblast growth factor and vascular endothelial growth factor expression in keratinocytes of burn scars. Eur Cytokine Netw. 2000; 11(2): 233-239.

18. Peruccio $D$, Castagnoli C, Stella M, D'Alfonso S, Momigliano PR, Magliacani $G$, et al. Altered biosynthesis of tumour necrosis factor (TNF) alpha is involved in postburn hypertrophic scars. Burns. 1994; 20(2):118-121. 